\title{
A short version of the Pain Anxiety Symptoms Scale (PASS-20): Preliminary development and validity
}

\author{
Lance $\mathrm{M}$ McCracken $\mathrm{PhD}^{1}$, Lara Dhingra $\mathrm{BA}^{2}$
}

LM McCracken, L Dhingra. A short version of the pain anxiety symptoms scale (PASS-20): Preliminary development and validity. Pain Res Manage 2002;7(1):45-50.

BACKGROUND: Research has shown significant relations between fear and avoidance of pain and the suffering and disability of chronic pain. Effective measurement tools have formed the foundation for studying these relations.

METHODS: The present article describes the initial development and validation of the PASS-20, a short form version of the Pain Anxiety Symptoms Scale (PASS). Like the original inventory, the PASS-20 measures fear and anxiety responses specific to pain. Items were selected for the short version based on item variance, item intercorrelation and reliability analyses.

RESULTS: The PASS-20 shows strong internal consistency, reliability, and good predictive and construct validity. Item reduction appears to result in minimal shrinkage of validity correlations.

CONCLUSIONS: Overall, the results suggest that the short form retains adequate psychometric properties. Possible research and clinical implications for the PASS-20 include more efficient screening during evaluations of patients with chronic pain, and use when the time or effort needed for the full version is prohibitive.

Key Words: Assessment, Avoidance, Chronic pain, Disability, Fear of pain, Pain-related anxiety

Version abrégée de l'échelle des symptômes d'anxiété à l'égard de la douleur (PASS-20) : élaboration et validité

CONTEXTE : La recherche a établi des liens significatifs entre la crainte et le comportement de fuite de la douleur ainsi qu'entre la souffrance et l'incapacité liée à la douleur chronique. L'on dispose maintenant d'outils efficaces de mesure pour étudier ces liens.

suite à la page suivante

\footnotetext{
${ }^{1}$ Pain Management Unit, Royal National Hospital for Rheumatic Disease and University of Bath, United Kingdom; ${ }^{2}$ Institute of Psychology, Illinois Institute of Technology, Chicago, Illinois, USA

Correspondence: Dr Lance M McCracken, Pain Management Unit, Royal National Hospital for Rheumatic Diseases, Bath BA1 1RL,

United Kingdom. Telephone +44-1225-473403, fax+44-1225-473461, e-mail lance.mccracken@rnhrd-tr.swest.nhs.uk

Received for publication December 19, 2000. Accepted February 5, 2001
} 
MÉTHODE : Le présent article décrit l'élaboration et la validation de la PASS-20, version abrégée de la Pain Anxiety Symptoms Scale (PASS). Tout comme le questionnaire originel, la PASS-20 mesure les réactions de crainte et d'anxiété causées par la douleur. Le choix des critères retenus pour la version abrégée repose sur leur variance, leur intercorrélation et les analyses de fiabilité.

RÉSULTATS : L'échelle PASS-20 a fait preuve d'une forte cohérence interne, de fiabilité et d'une bonne validité prédictive et conceptuelle. La diminution du nombre de paramètres ne s'est que très faiblement répercutée sur les corrélations de validité.

CONCLUSION : Dans l'ensemble, les résultats semblent indiquer que la version abrégée possède de bonnes propriétés psychométriques. Parmi les sujets possibles de recherche sur la PASS-20 et son utilisation en clinique, mentionnons une détection plus efficace durant l'évaluation des patients souffrant de douleurs chroniques et son application lorsque le temps ou les ressources ne permettent pas d'avoir recours à la version complète.
T $\mathrm{t}$ is widely regarded that for some individuals with 1 chronic pain, anxiety or fear responses to pain or movement contribute significantly to their suffering and disability (1-4). Two excellent reviews have been written presenting, clarifying and elaborating cognitive-behavioural models of 'fear-avoidance' in chronic pain $(5,6)$.

In 1995, we proposed three mechanisms that may link pain-related anxiety responses to patient suffering and disability (7). First, we pointed to a repeating and self-perpetuating cycle of pain, avoidance, behavioural deactivation and physical deconditioning. This can be a particularly troubling cycle because it can be easily complicated by issues such as depression. Second, we noted the attentiondisrupting effects of subjective anxiety, implying that feeling anxious distracts a person from effective behaviour and successful problem-solving. Finally, we discussed the potential for pain-related anxiety to include extreme or persistent physiological arousal in particular tissues such as muscles. These tissues might then become irritated or sensitized to other painful stimuli. In a later study (8), we proposed that pain-related anxiety responses might lead the patient to experience and perceive more physical symptoms, evaluate their health as poor as a result of those symptoms and behave in other ways consistent with their perceived poor health. They might then focus more on health issues to the exclusion of other concerns and seek more health care (8).

Naturally, the development of instruments that measure fear and anxiety responses to pain has mirrored and supported the conceptual and empirical work in this area. The present paper focuses on one of these measures, the Pain Anxiety Symptoms Scale (PASS) (1). We will first review findings examining the psychometric properties and usefulness of the PASS in pain assessment and then describe a study to develop a shortened version of the instrument.

Standardized psychometric data for the 40-item PASS was obtained based on analyses of 250 patients referred to a university pain clinic $(7,9)$. Results showed that the four PASS subscales (labelled 'Cognitive', 'Escape and Avoidance', 'Fear', 'Physiological Anxiety') are moderately intercorrelated $(\mathrm{r}=0.51$ to $\mathrm{r}=0.75$ excluding correlations with total score). The four subscales and the total scale are internally consistent (alpha=0.74 to alpha=0.94) and achieve good test-retest reliability over roughly two weeks $(r=0.74$ to $r=0.87)$. Analyses of demographic variables show that PASS scores are independent of pain duration, location, sex or marital status. However, they do correlate with age, employment status, educational level and sedative medication use $(7,9)$.

Since its introduction in 1992, the PASS has garnered significant evidence for validity as a measure of pain-related anxiety and fear $(1,7,9-14)$. To summarize some pertinent findings, scores from the PASS have been shown to correlate with general measures of pain severity, anxiety and depression $(1,14,15)$; disability $(1,12)$; passive range of motion and anxiety ratings during a physical examination (11); greater catastrophizing responses to pain $(4,10)$, and fewer pain coping responses $(10,15)$; anxiety sensitivity $(16,17)$, hypervigilance and preoccupation with pain (13); and general physical complaints (8), and reduced lifting and carrying capacity (14). We have shown that PASS scores predict disability better than, and beyond variance attributed to, depression, general anxiety or pain (1). More recent studies have shown that the PASS discriminates multivariate, empirical subtypes of dysfunctional patients from adaptive copers with chronic pain $(18,19)$. Finally, PASS scores are sensitive to the effects of multidisciplinary treatment for chronic pain. Reduction in pain-related anxiety, as measured by the PASS, predicts improvement from treatment on other outcomes (20).

Past research has also examined the utility of differing measures of anxiety. These studies have compared measures of anxiety specifically related to the patient's pain, anxiety associated with varied pain stimuli and a general measure that does not specify the source of anxiety. Results showed that PASS scores were significantly more correlated with measures of pain, disability, avoidance and complaints than the Spielberger Trait Anxiety Inventory (21), and more correlated with pain and disability than the Fear of Pain Questionnaire (22). The results showed that assessment with the PASS that includes cognitive, motoric and physiological anxiety responses to the patient's particular pain provides greater ability to predict the magnitude of suffering and disability due to pain than that achieved with more general measures of anxiety. A recent study further confirmed that the PASS predicts patients' physical functioning beyond the contributions of depression, general anxiety and pain (14).

The PASS was developed to evaluate pain-related anxiety and fear in individuals with chronic pain disorders. Theory and research support the scale's use of a model of anxious distress that includes multiple behavioural modalities, including cognitive, motoric and physiological 
responses specific to the experience of chronic pain. Both the psychometric properties of the PASS and its clinical utility are well established. However, the 40-item format may be too lengthy for some clinical or research applications where there is concern about the time and the amount of effort asked of subjects. The purpose of the present article is to describe the revision of the 40-item PASS to a shorter, 20-item assessment instrument.

\section{SUBJECTS AND METHODS}

\section{Subjects}

Subjects were 282 consecutive patients with chronic pain seeking treatment in a university pain management centre. The mean age of the sample was 46.5 years $(\mathrm{SD}=13.8)$. Most were women $(66.0 \%)$, married $(53.5 \%$; $22.3 \%$ single, $16.7 \%$ divorced, $7.4 \%$ widowed) and white $(75.5 \%$; $20.6 \%$ black, $1.8 \%$ Asian, $1.8 \%$ Hispanic, $0.4 \%$ other). Average education was 13.8 years $(\mathrm{SD}=2.7)$. Most patients suffered from back pain $(55.4 \%$; $14.2 \%$ lower limbs, $8.2 \%$ upper limbs, $7.1 \%$ cervical, $5.3 \%$ thoracic, $9.8 \%$ other). The median duration of pain was 32 months (range three to 372 months). All patients completed a demographic questionnaire, a $100 \mathrm{~mm}$ visual analogue pain measure and the measures described below during their initial evaluation.

\section{Measures}

Beck Depression Inventory: The Beck Depression Inventory (BDI) (23) is a 21-item self-report measure assessing cognitive and vegetative symptoms of depression. Research evaluating the psychometric properties of the BDI has indicated that scores from this inventory are reliable and valid indexes of depression (24).

PASS: Pain-related anxiety responses were assessed with the PASS. The PASS assesses pain-specific anxiety symptoms and consists of four 10-item subscales measuring cognitive anxiety responses, escape and avoidance, fearful thinking and physiological anxiety responses. All items are rated on a frequency scale from 0 (never) to 5 (always). As discussed above, the PASS subscales have demonstrated satisfactory internal consistency, test-retest reliability and validity (7).

Sickness Impact Profile: The Sickness Impact Profile (SIP) (25) is a 136-item checklist. The items are behaviourally based and assess the effect of illness on 12 categories of daily activity. Subjects endorse statements that describe current problems with functioning related to their health. The SIP provides an overall impact score as well as separate composite scores for physical and psychosocial dimensions. Research has shown that the SIP has satisfactory internal consistency, test-retest reliability and validity (25).

\section{RESULTS}

Four sets of item intercorrelation analyses were conducted focusing on each of the original four 10-item subscales. Items were selected for the shortened scale in sequence based on the magnitude of their corrected item-total corre-
TABLE 1

Corrected item-total correlations between items selected for the short form of the Pain Anxiety Symptoms Scale and the original Pain Anxiety Symptoms Scale subscales

Corrected

Subscale Item item-total $r$

Cognitive

I can't think straight when in pain

During painful episodes it is difficult for me

to think of anything besides the pain

When I hurt I think about pain constantly

I find it hard to concentrate when I hurt

I worry when I am in pain

Escape/avoidance

I go immediately to bed when I feel severe pain

0.52

I will stop any activity as soon as I sense pain coming on

As soon as pain comes on I take medication to reduce it

I avoid important activities when I hurt

I try to avoid activities that cause pain

Fear

I think that if my pain gets too severe, it will never decrease

When I feel pain I am afraid that something terrible will happen

When I feel pain I think that I might be seriously ill

Pain sensations are terrifying

When pain comes on strong I think that I might become paralysed or more disabled

Physiological anxiety

I begin trembling when engaged in an activity that increases pain

Pain seems to cause my heart to pound or race

When I sense pain I feel dizzy or faint

Pain makes me nauseous

I find it difficult to calm my body down lation. In two cases, items selected had low mean ratings and variances, and contributed to reduced scale variability (the Fear item, "18. I think I have a serious medical problem that my physician has failed to uncover." and the Physiological item, "28. I have trouble catching my breath 
TABLE 2

Correlations between the original Pain Anxiety Symptoms Scale (PASS) scales and the shortened scales

\begin{tabular}{lccccc}
\hline & \multicolumn{5}{c}{ Original PASS subscales } \\
$\begin{array}{l}\text { PASS-20 } \\
\text { subscales }\end{array}$ & Cognitive & $\begin{array}{c}\text { Escape/ } \\
\text { avoidance }\end{array}$ & $\begin{array}{c}\text { Fear } \\
\text { Physiological } \\
\text { anxiety }\end{array}$ & Total \\
\hline Cognitive & 0.95 & 0.58 & 0.69 & 0.63 & 0.85 \\
$\begin{array}{l}\text { Escape/ } \\
\text { avoidance }\end{array}$ & 0.53 & 0.93 & 0.42 & 0.44 & 0.68 \\
$\begin{array}{l}\text { Fear } \\
\begin{array}{l}\text { Physiological } \\
\text { anxiety }\end{array}\end{array}$ & 0.61 & 0.51 & 0.94 & 0.66 & 0.83 \\
$\begin{array}{l}\text { Total } \\
\text { All correlations significant at } P<0.001\end{array}$ & 0.48 & 0.65 & 0.96 & 0.83 \\
\end{tabular}

All correlations significant at $P<0.001$

TABLE 3

Correlations of the original Pain Anxiety Symptoms Scale (PASS) subscales and the shortened PASS subscales with pain, depression and disability

\begin{tabular}{|c|c|c|c|c|}
\hline & Pain & Depression & $\begin{array}{l}\text { Physical } \\
\text { disability }\end{array}$ & $\begin{array}{c}\text { Psychosocial } \\
\text { disability }\end{array}$ \\
\hline \multicolumn{5}{|c|}{ Original PASS subscales } \\
\hline Cognitive & 0.30 & 0.67 & 0.33 & 0.61 \\
\hline $\begin{array}{l}\text { Escape/ } \\
\text { avoidance }\end{array}$ & 0.24 & 0.39 & 0.39 & 0.37 \\
\hline Fear & 0.35 & 0.55 & 0.36 & 0.52 \\
\hline $\begin{array}{l}\text { Physiological } \\
\text { anxiety }\end{array}$ & 0.32 & 0.53 & 0.41 & 0.56 \\
\hline Total & 0.36 & 0.64 & 0.44 & 0.61 \\
\hline \multicolumn{5}{|c|}{ Shortened PASS subscales } \\
\hline Cognitive & 0.30 & 0.61 & 0.30 & 0.54 \\
\hline $\begin{array}{l}\text { Escape/ } \\
\text { avoidance }\end{array}$ & 0.20 & 0.38 & 0.35 & 0.35 \\
\hline Fear & 0.32 & 0.52 & 0.38 & 0.51 \\
\hline $\begin{array}{l}\text { Physiological } \\
\text { anxiety }\end{array}$ & 0.30 & 0.54 & 0.41 & 0.55 \\
\hline Total & 0.34 & 0.63 & 0.44 & 0.59 \\
\hline
\end{tabular}

All correlations significant at $P<0.001$. Pain was measured with a $100 \mathrm{~mm}$ visual analogue scale. Depression was measured with the Beck Depression Inventory. Disability was measured with the Sickness Impact Profile

when I have pain sensations."). In those cases, the item with the next largest corrected item-total correlation was selected. Based on repeat reliability analyses, it was found that the PASS subscales could be reduced to five-item scales and retain satisfactory reliability and variance (average alpha $=0.81$, range 0.75 to 0.87 ). Table 1 shows the 20 selected items along with their corrected correlation to the original subscales.
TABLE 4

Means, standard deviations and internal consistency (alpha, reliability) values for the revised, shortened Pain Anxiety Symptoms Scale subscales and the total score $(n=282)$

\begin{tabular}{lrlc}
\hline Subscale & Mean & (SD) & Alpha \\
\hline Cognitive & 12.27 & $(6.73)$ & 0.86 \\
Escape/avoidance & 12.84 & $(6.11)$ & 0.75 \\
Fear & 7.37 & $(6.38)$ & 0.82 \\
Physiological anxiety & 6.15 & $(5.69)$ & 0.81 \\
Total & 38.62 & $(20.38)$ & 0.91 \\
\hline
\end{tabular}

Subscale scores range from 0 to 25 , and the total scores range from 0 to 100

Next, a series of analyses were conducted to examine the interrelations between the original PASS subscales and the subscales of the proposed shortened version (Table 2). The correlations between the original subscales and the matching shortened versions were very high (range $r=0.93$ to $r=0.97$, average $r=0.95$ ). The correlations between the shortened subscales and their nonmatching counterparts among the original subscales, excluding the total score, were lower (range $\mathrm{r}=0.42$ to $\mathrm{r}=0.71$, average $\mathrm{r}=0.57$ ). Hence, the shortened subscales showed good convergent and divergent validity.

Because shortening the subscales includes some loss of information and variability, this could affect the validity correlations of the new scales and their ability to predict other important patient behaviours. To test for this potential problem, parallel analyses were performed. Correlations were calculated for both the original and the shortened scales of the PASS, with measures of pain, depression and disability (Table 3 ). A coefficient by coefficient comparison shows that they are remarkably similar. The most discrepant pairs were depression and the original and the shortened Cognitive subscales of the PASS $(r=0.67$ and $r=0.61$, respectively), and psychosocial disability and these same subscales $(r=0.61$ and $r=0.54)$. These coefficients were significantly different based on a test using Fisher's $Z$ transformation $(P<0.01)$. However, the large sample size and high intercorrelation between the original and the shorter Cognitive subscales contributed substantially to those results. None of the other 18 of 20 pairs of correlations differed significantly.

Mean values, standard deviations and alpha coefficients for the shortened subscales and the total score are included in Table 4. All the shortened subscales have good to excellent internal consistency. The internal consistency value for the total is perhaps higher than desired.

\section{DISCUSSION}

The present paper describes the development of a 20-item version of the PASS (PASS-20) based on analyses conducted on the original 40 items. We provide evidence that the shortened PASS subscales retain good internal consistency, criterion validity and construct validity. Three main find- 
ings support the utility of the short version. First, through an iterative process of item intercorrelations, we showed that reducing the PASS subscales to five-item scales maintains satisfactory internal consistency (mean alpha $=0.81$ ). Second, we showed that intercorrelations between the shortened scales and the matching originals were high (mean $\mathrm{r}=0.95$ ), while correlations with nonmatching original scales were relatively low (mean $r=0.57$ ). These results support good convergent and divergent validity. Third, correlations for both the original and the shortened versions of the PASS with measures of pain, depression and disability were remarkably similar, supporting predictive and construct validity of the shorter version.

The rationale for the development of a short version of the PASS was to make the assessment of pain-related anxiety responses more accessible in clinical and research contexts. In the past, limited time or patient tolerance for forms may have prevented it from being used. Clinically, the short version is likely to be a useful screen for significant anxious responses to chronic pain, and it is likely to be a useful treatment outcome measure. It may be useful when multiple repeated assessments are needed, although we have not directly assessed its temporal stability. It may have applications in the study of behavioural treatment processes and in laboratory situations where subjects' tendencies to respond anxiously to pain are compared with responses to laboratory challenges or tests.

Obviously, anxiety is a complex construct. There is some risk in attempting to measure it with brief instruments. For example, with the PASS, we attempted to quantify escape and avoidance. The shortened scale attempts to do this with just five items. It should be obvious that this is a small sample from a large domain. Functionally, the entire class of avoidance behaviour can be extremely mixed, including rest, medication use, alcohol use, grimacing, complaints, refusal to exercise, distraction, limping, absenteeism, using assistive devices or requesting assistance, in a variety of situations. Likewise, fearful thinking about pain can take highly varied and idiosyncratic forms. Our data support the validity of the 20 -item instrument. However, as with any

\section{REFERENCES}

1. McCracken LM, Zayfert C, Gross RT. The Pain Anxiety Symptoms Scale: development and validation of a scale to measure fear of pain. Pain 1992;50:67-73.

2. Vlaeyen JWS, Kole-Snijders AMJ, Boeren RGB, vanEek H. Fear of movement/(re)injury in chronic low back pain and its relation to behavioral performance. Pain 1995;62:363-72.

3. Vlaeyen JWS, Kole-Snijders AMJ, Rotteveel A, Ruesink R, Heuts PHTG. The role of fear of movement/(re)injury in pain disability. J Occup Rehabil 1995;5:235-52.

4. Crombez G, Vlaeyen JWS, Heuts PHTG, Lysens R. Pain-related fear is more disabling than pain itself: evidence on the role of pain-related fear in chonic back pain disability. Pain 1999;80:329-39.

5. Asmundson GJG, Norton PJ, Norton GR. Beyond pain: the role of fear and avoidance in chronicity. Clin Psychol Rev 1999;19:97-119.

6. Vlaeyen JWS, Linton SJ. Fear-avoidance and its consequences in chronic musculoskeletal pain: a state of the art. Pain 2000;85:317-32. short instrument, there will be patients who show significant behavioural responses in a domain but do not score significantly in that domain because the instrument did not sample the responses pertinent to them.

The item selection procedures employed could be criticized for relying too heavily on item correlations with the original scales and focusing too much on internal consistency. Naturally, these processes could result in information loss and restricted variability. We attempted to address that concern. We rejected items that clearly reduced scale variability in two cases. The average corrected item-total correlation for selected items was $r=0.59$. Squaring that value shows that $35 \%$ of the variance of the average item overlaps with the remaining items of the scale. We know of no rules to assess that value, but it appears adequate. Finally, the validity analyses were the ultimate item selection procedure. Because there was minimal shrinkage in the magnitude of the correlations between the shortened scales and the measures of pain, depression and disability compared with the original scales, we consider the selected items to be adequate.

Replication of these results is needed. Certainly, because we relied heavily on the selection of items based on itemtotal correlations, correlations between the short scales and the original scales were guaranteed. One would need to see high, significant correlations between those sets of scales in a sample other than the sample where the short subscales were derived to cross-validate our results. Some shrinkage of those coefficients would be expected.

We believe that the short version of the PASS should be considered as an alternative version when the need for brevity outweighs other concerns. We do not consider it to be a better replacement for the original. Our experience with the 20-item version is brief compared with nine years of experience with the original. As with any instrument, one should not automatically accept it as sound for a particular use but scrutinize it constantly. We still recommend the original version when space and time allow it, both clinically and in research applications. Further study should sort out the strengths and limits of the PASS-20, and show the situations when it is most useful.
7. McCracken LM, Gross RT. The Pain Anxiety Symptoms Scale (PASS) and the assessment of emotional responses to pain. In: VandeCreek L, Knapp S, Jackson TL, eds. Innovations in Clinical Practice: A Sourcebook, vol 14. Sarasota: Professional Resources Press, 1995:309-21.

8. McCracken LM, Faber SD, Janeck AS. Pain-related anxiety predicts non-specific physical complaints in persons with chronic pain. Behav Res Ther 1998;36:621-30.

9. McCracken LM, Zayfert C, Gross RT. The Pain Anxiety Symptoms Scale: a multimodal measure of pain-specific anxiety. The Behavior Therapist 1993;16:183-4.

10. McCracken LM, Gross RT. Does anxiety affect coping with chronic pain? Clin J Pain 1993;9:253-9.

11. McCracken LM, Gross RT, Sorg PJ, Edmands TA. Prediction of pain in patients with chronic low back pain: effects of inaccurate prediction and pain-related anxiety. Behav Res Ther 1993;31:647-52.

12. McCracken LM, Gross RT, Aikens J, Carnrike CLM. The assessment 
of anxiety and fear in persons with chronic pain: a comparison of instruments. Behav Res Ther 1996;34:927-33.

13. McCracken LM. "Attention" to pain in persons with chronic pain: A behavioral approach. Behav Ther 1997;28:271-84.

14. Burns JW, Mullen JT, Higdon LJ, Wei JM, Lansky D. Validity of the Pain Anxiety Symptoms Scale (PASS): prediction of physical capacity variables. Pain 2000;84:247-52.

15. Strahl C, Kleinknecht RA, Dinnel DL. The role of pain anxiety, coping, and pain self-efficacy in rheumatoid arthritis patient functioning. Behav Res Ther 2000;38:863-73.

16. Asmundson GJG, Norton GR. Anxiety sensitivity in patients with physically unexplained chronic back pain: a preliminary report. Behav Res Ther 1995;33:771-7.

17. Asmundson GJG, Taylor S. Role of anxiety sensitivity in pain-related fear and avoidance. J Behav Med 1996;19:577-86.

18. Asmundson GJG, Norton GR, Allerdings MD. Fear and avoidance in dysfunctional chronic back pain patients. Pain 1997;69:231-6.

19. McCracken LM, Spertus IL, Janeck AS, Sinclair DS, Wetzel FT. Behavioral dimensions of adjustment in persons with chronic pain: pain-related anxiety and acceptance. Pain 1999;80:283-9.
20. McCracken LM, Gross RT. The role of pain-related anxiety reduction in the outcome of multidisciplinary treatment for chronic low back pain: preliminary results. J Occup Rehabil 1998;8:179-89.

21. Spielberger CD, Gorsuch RL, Lushene PR, Vagg PR, Jacobs GA. Manual for the State-Trait Anxiety Inventory (Form Y). Palo Alto: Consulting Psychologist Press, 1983.

22. McNeil DW, Rainwater AJ, Al-Jazireh L. Development of a methodology to measure fear of pain. The Annual Meeting of the Association for Advancement of Behaviour Therapy. Chicago, November 13 to $16,1986$.

23. Beck AT, Ward CH, Mendelson M, Mock J, Erbaugh J. An inventory for measuring depression. Arch Gen Psychiatry 1961;4:561-71.

24. Beck AT, Steer RA, Garbin MG. Psychometric properties of the Beck Depression Inventory: twenty-five years of evaluation. Clin Psychol Rev 1988;8:77-100.

25. Bergner M, Bobbitt RA, Carter WB, Gilson BS. The Sickness Impact Profile: development and final revision of a health status measure. Med Care 1981;29:787-805. 


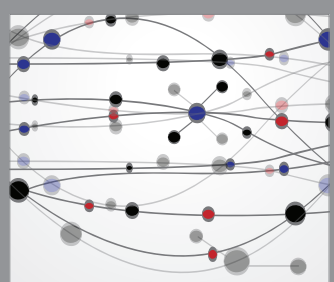

The Scientific World Journal
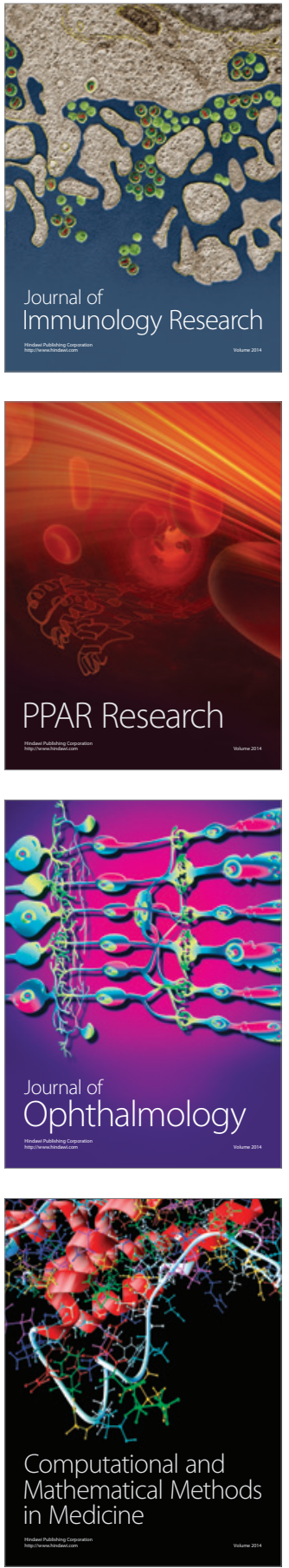

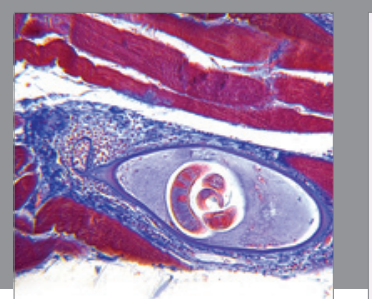

Gastroenterology Research and Practice

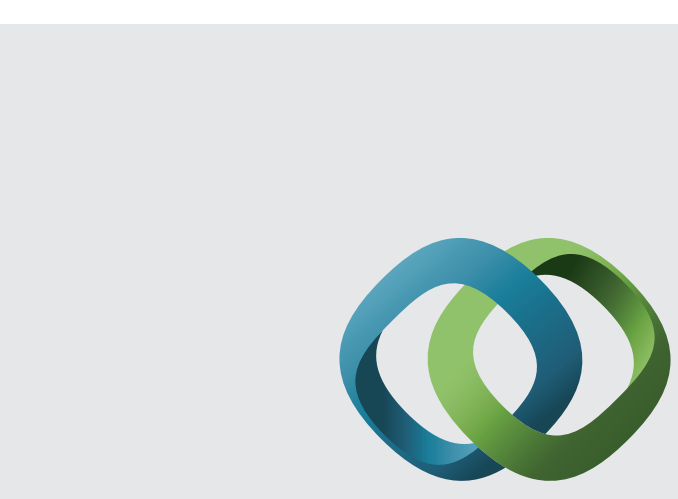

\section{Hindawi}

Submit your manuscripts at

http://www.hindawi.com
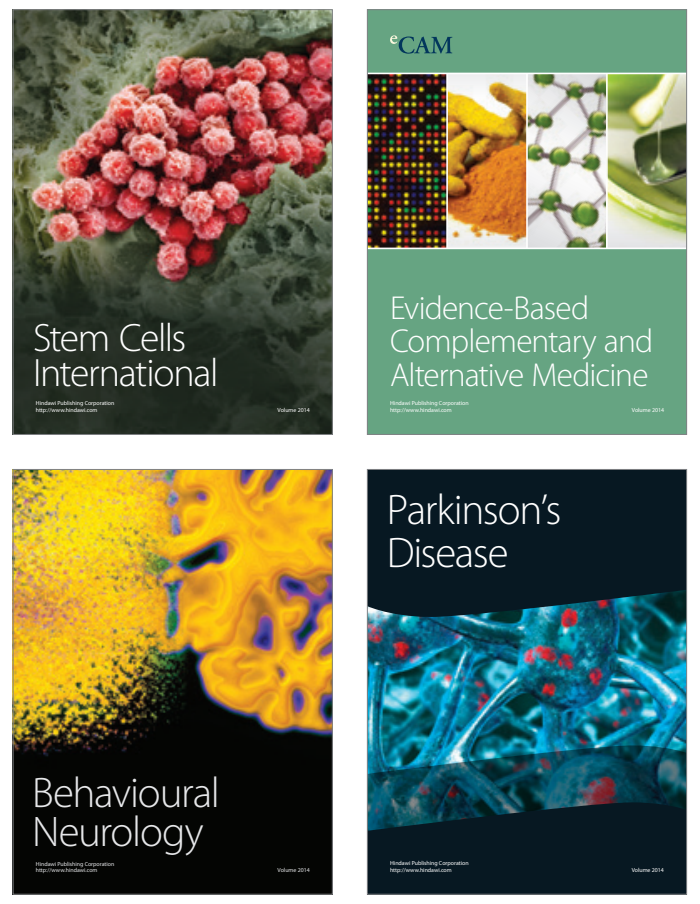
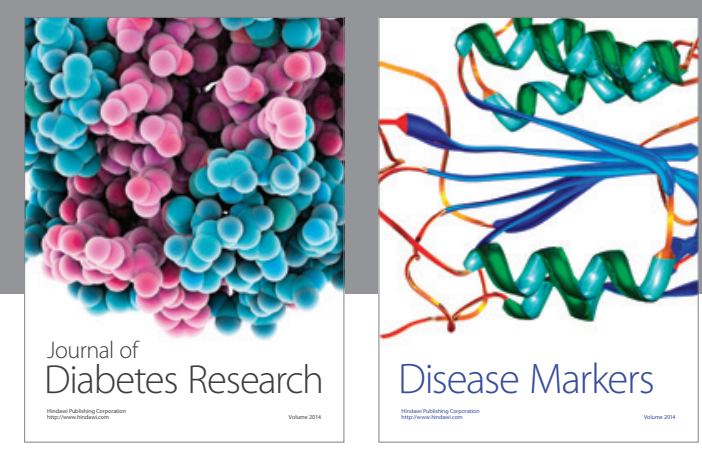

Disease Markers
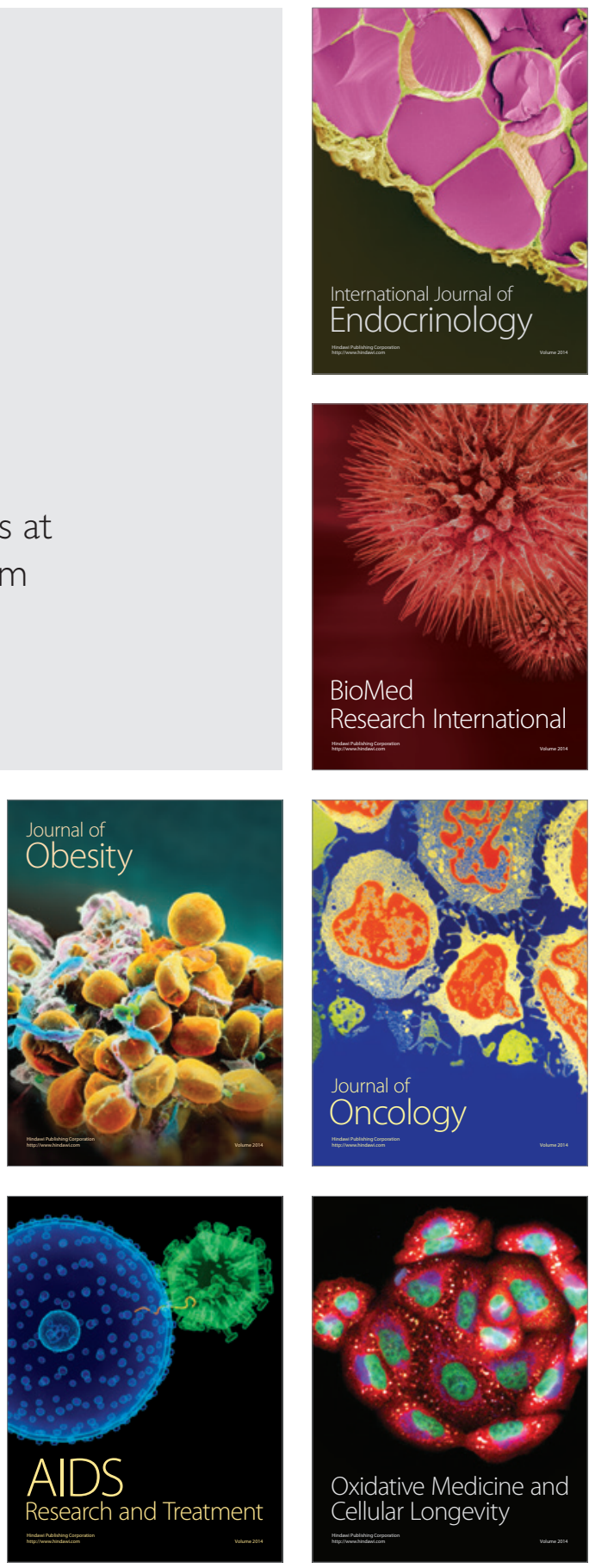